\title{
Prevalence and Trends of Congenital Anomalies Among Neonates at Jimma Medical Center, Jimma, Ethiopia: A Three-Year Retrospective Study
}

This article was published in the following Dove Press journal:

Pediatric Health, Medicine and Therapeutics

\author{
Mulualem Silesh (D) \\ Tesfanesh Lemma (iD) \\ Belete Fenta ${ }^{2}$ \\ Tsegaw Biyazin (iD) ${ }^{2}$ \\ 'Department of Midwifery, College of \\ Health Science and Medicine, Debre \\ Berhan University, Debre Berhan, \\ Ethiopia; ${ }^{2}$ School of Nursing and \\ Midwifery, Institute of Health, Faculty of \\ Health Sciences, Jimma University, Jimma, \\ Ethiopia
}

Introduction: Congenital anomalies are a major public health problem which is defined as structural or functional anomalies that occur during intrauterine life which can be detected prenatally, at birth, or sometimes may only be detected later in infancy. The impact of congenital anomalies is severe in middle- and low-income countries than in other developed and developing countries.

Objective: To assess the prevalence and trends of congenital anomalies among neonates admitted at Jimma Medical Center from 2017 to 2019.

Methods: A facility-based retrospective, descriptive crossectional study was conducted among neonates admitted at Jimma Medical Center from 2017-2019. Descriptive analysis (frequency and percentage) was calculated for the variables. The result was present in the table, text, and figure.

Results: From a total of 3346 admitted neonates, 199 (5.95\%) neonates were diagnosed with congenital anomalies; of which 120 (60.3\%), 146 (73.4\%), 144 (72.4\%) and $30(15.1 \%)$ of neonates were males, urban dwellers, delivered with normal birth weight and had multiple congenital anomalies, respectively. Central nervous system was the most commonly affected body system 56 (28.1\%), followed by the gastrointestinal tract 41 (20.1\%) and musculoskeletal system 32 (16.1\%). The proportion of congenital anomalies was significantly increasing over time. Conclusion: The overall prevalence of congenital anomalies was high and increased from year to year. The proportions observed in the study indicated that a significant number of neonates were affected and suffered from the impacts of congenital anomalies which need immediate preventive actions such as iron folate supplementation during preconception and early pregnancy. Therefore, design strategies to create community awareness and prevention mechanism of congenital anomalies, and strengthening the care and rehabilitation services for affected patients are crucial.

Keywords: congenital anomalies, Jimma Medical Center, Ethiopia

\section{Introduction}

Congenital anomalies (CAs) are also known as birth defects, congenital disorders, or congenital malformations. ${ }^{1}$ Congenital anomalies are a major public health problem $^{2}$ which is defined as structural or functional anomalies that occur during intrauterine life which can be detected prenatally, at birth, or in later life stages. ${ }^{1}$ Congenital anomalies contribute to permanent disability and death of children in both developed and developing countries which has a significant impact on individuals, families, health-care systems, and communities. ${ }^{1,3}$
Correspondence: Mulualem Silesh Department of Midwifery, College of Health Sciences, Debre Berhan University, Debre Berhan, Ethiopia Tel +251920249873

Email sileshmulualem22@gmail.com 
The etiologies of birth defects are thought to be a multifactorial inheritance, environmental teratogens, micronutrient deficiencies, chromosomal disorders, and single gene defects. Also, in developing countries, maternal infectious diseases (such as rubella and syphilis) the common causes of CAs. ${ }^{4}$ Congenital anomalies are usually subdivided into two; minor and major anomalies. A minor anomaly is defined as structural abnormality present at birth, having minimal effect on clinical function, while major CAs are conditions that are severe enough to reduce life expectancy or compromise normal function may lead to difficulty to survive or results in stillbirth/infant death. ${ }^{5}$

Worldwide, around 3.3 million children below the age of 5 years die of birth defects annually and 3.2 million live-born children are disabled for life $\mathrm{e}^{3}$ and an estimated of 303,000 neonates die within the first 28 days of life every year from congenital anomalies. ${ }^{1,3}$ The impact of congenital anomalies is severe in middle- and low-income countries; $95 \%$ of the children who die from CAs were in middle- and low-income countries than other countries. ${ }^{1,6}$ The study conducted in Malta revealed that congenital anomalies accounted for $36.7 \%$ of the neonatal mortality. ${ }^{7}$ In the study done in Nigeria mortality rate among neonates with CA was $10.4 \%{ }^{8}$ According to the estimates generated by world health organization (WHO) and maternal and child epidemiology estimation group (MCEE), among the leading cause of neonatal mortality in Ethiopia CAs accounts for $11 \%{ }^{9}$

According to findings from different reviewed literatures, the proportion of congenital anomalies varied from country to country; in which $4.24 \%$ in Pakistan, ${ }^{10} 0.6 \%$ in Hong Kong, ${ }^{11} 1.85 \%$ in India, ${ }^{12} 29 \%$ in Tanzania, ${ }^{13} 2.5 \%$ in Egypt, ${ }^{4}$ and $1.99 \%$ in Ethiopia. ${ }^{14}$

Despite of having knowledge on the prevention of CAs (such as vaccination, adequate intake of folic acid or iodine through fortification of foods or supplementation, and early antenatal care), ${ }^{1,13}$ only $1.92 \%$ of pregnant women took the folic acid supplement at a protective period against neural tube defects (NTDs) and 11.6\% of pregnant women started in the first trimester of pregnancy ${ }^{15}$ which contributes for the increments of the prevalence of CAs and its impact in developing countries including Ethiopia. Therefore, the main aim of this study was to determine the prevalence and trends of congenital anomalies among neonates admitted at Jimma Medical Center, Jimma, Ethiopia.

\section{Methods and Materials}

\section{Study Design, Area and Period}

A facility-based retrospective, descriptive crossectional study was conducted at Jimma Medical Center (JMC) which is located in Jimma town, Jimma zone, $352 \mathrm{Km}$ in the south west of Addis Ababa, the capital city of Ethiopia. Jimma Medical Center is the only hospital having a neonatal intensive care unit (NICU) unit in Jimma Zone and, one of the oldest university specialized hospital in the country established in 1922 and providing service for more than 15 million people in the catchment area. Currently, it is the only teaching and referral hospital in the southwestern part of the country. A study was conducted from 2017-2019.

\section{Study Population}

All neonates who were admitted from January $1 / 2017$ to December 30/2019 at JMC were included in the study and neonates with incomplete information were excluded.

\section{Data Collection Tool and Procedure}

Data were collected from records of neonates' medical registration books from February 14-30, 2020. All information among neonates' with congenital anomaly were collected by using checklist which was adapted from a retrospective descriptive study conducted at Addis Abeba. ${ }^{16}$ The checklist contained study participants' medical record number (MRN), sex, residence, weight at birth, mode of delivery, terms of pregnancy, outcome/discharge status, year of diagnosis and type of congenital anomalies. Three BSc midwives and one MSc students were involved for data collection and supervision, respectively. Also, training was provided for both data collectors and supervisor about the data collection tool and procedure.

\section{Data Analysis and Quality Control}

Descriptive statistics (frequency and percentages) were used to describe the prevalence and the trend of CAs. The prevalence rate of $\mathrm{CA}$ was calculated as the proportion of neonates with CAs (numerator) among the total number of neonates admitted (denominator) during the study period. The result was presented in text, tables, and figures. Both data collectors and supervisors were trained for one day on data collection procedure before the actual data collection period. The supervisor checked all filled questionnaires daily the completeness of the checklist and obstetricians/pediatricians/head of neonatology ward (Nurse) were consulted when there was an ambiguous/unclear diagnosis. 


\section{Result}

A total of 3346 neonates were admitted at JMC neonatal intensive care unit (NICU) within three years of study period. One hundred ninety nine $(5.95 \%)$ of neonates were noted to have congenital anomalies. From total neonates diagnosed with congenital anomalies, 120 (60.3\%) of them were males, 146 (73.4\%) were urban dwellers, and $144(72.4 \%)$ neonates delivered with normal birth weight (2.5 to $4 \mathrm{Kg})$. The majority of $129(64.8 \%)$ of the neonates with congenital anomalies have been discharged with positive outcomes (recovered) from their problem at JMC (Table 1). Central nervous system (CNS) was the most affected body system by CAs 56 (28.1\%), followed by the gastrointestinal tract (GIT) $41(20.1 \%)$ and musculoskeletal system (MSS) 32 (16.1\%) respectively (Figure 1).

Of the total neonates with congenital anomalies, about $30(15.07 \%)$ of the neonates had multiple CAs, and 169 (84.92\%) had single CAs; of which the most commonly diagnosed CAs were spinal bifida 29 (14.57\%), club foot $25(12.56 \%)$ and imperforate anus $19(9.55 \%)$ respectively (Table 2). The linear trend of the proportion of CAs over the three year period were $18(3 \%), 79(6.1 \%)$, and 102 (7.1\%) respectively; which indicated that there was a significant increase in a linear trend over time (Figure 2).

Table I Frequency Distribution of Congenital Anomalies in Relation to Neonatal Characteristics Among Neonates with Congenital Anomalies at Jimma Medical Center, Ethiopia from 2017 to $2019(n=199)$

\begin{tabular}{|l|l|c|c|}
\hline Variables & Category & $\begin{array}{c}\text { Number } \\
\text { (n) }\end{array}$ & $\begin{array}{c}\text { Percent } \\
\text { (\%) }\end{array}$ \\
\hline Sex of neonate & Male & 120 & 60.3 \\
& Female & 79 & 39.7 \\
\hline Residence & Urban & 146 & 73.4 \\
& Rural & 53 & 26.6 \\
\hline \multirow{2}{*}{ Weight at birth } & Normal birth weight $(2.5-4 \mathrm{~kg})$ & 144 & 72.4 \\
& Low birth weight $(<2.5 \mathrm{~kg})$ & 55 & 27.6 \\
\hline \multirow{2}{*}{ Terms of } & Term & 128 & 64.3 \\
pregnancy & Pre term & 66 & 33.2 \\
& Post term & 5 & 2.5 \\
\hline \multirow{2}{*}{ Mode of delivery } & Vaginal & 160 & 80.4 \\
& Cesarean section & 39 & 19.6 \\
\hline \multirow{2}{*}{ Discharge status } & Recovered & 129 & 64.8 \\
& Transferred to other facility & 44 & 22.1 \\
& Dead & 26 & 13.1 \\
\hline
\end{tabular}

Note: ${ }^{a}$ Neonates with anencephaly and had comorbidity conditions (congenital anomalies with asphyxia and/preterm and/low birth weight/sepsis).

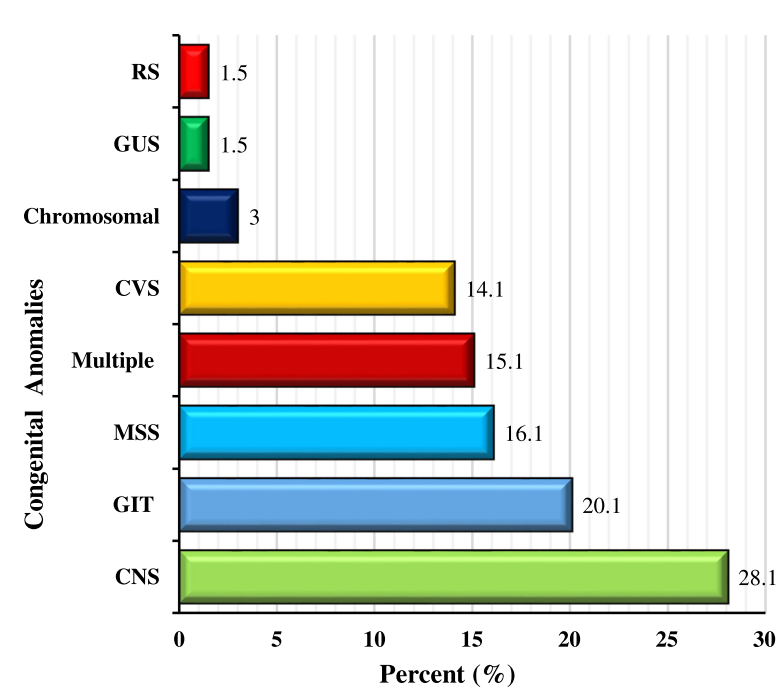

Figure I Frequency distribution of congenital anomalies by body system among neonates with congenital anomalies at Jimma Medical Center, Ethiopia from 2017 to $2019(n=199)$.

\section{Discussion}

The findings of this study showed that there was an increasing linear trend of CAs over time and the overall prevalence of congenital anomalies was 199 (5.95\%) which is comparable with the findings of studies conducted in Korea $(5.48 \%)^{17}$ and Nigeria $(6.3 \%){ }^{8}$ However, lower than studies done in Tanzania $29 \%,{ }^{13}$ and Dessie, Ethiopia $8.4 \% .{ }^{18}$ This might be due to sample size differences; in Tanzania, the study was conducted among 445 admitted infants who were less than 2 months age and in Dessie, Ethiopia the study was done by involving 462 live births. However, in this study 3346 neonates' medical records were reviewed.

The prevalence of CAs in this study higher than the studies conducted in Pakistan 4.24\%, ${ }^{10}$ Nigeria 2.8\%, ${ }^{19}$ United States of America (USA) $2.89 \%,{ }^{20}$ Italy $2.46 \%,{ }^{21}$ Canada $3.66 \%,{ }^{22}$ Iran $0.85 \%,{ }^{23}$ India $1.85 \%,{ }^{12}$ Egypt $2.5 \%,{ }^{4}$ Ethiopia $1.9 \%$ and $1.99 \% .{ }^{14,16}$ The variation might be due to the difference in sample size, study population and sociodemographic characteristics. In Pakistan and Nigeria, the studies were conducted among $2360^{10}$ and $607^{19}$ patients admitted at NICU, respectively. Whereas the current study was done among 3346 neonates admitted at NICU. The studies in the USA, Italy, Canada, India, Iran, and Egypt were conducted among live births and in Ethiopia the studies were conducted among babies/ children aged 0-17 years. But, the current study was conducted among neonates admitted at JMC neonatology 
Table 2 Frequency Distribution of Congenital Anomalies by Type Among Neonates with Congenital Anomalies at Jimma Medical Center, Ethiopia from 2017 to $2019(n=199)$

\begin{tabular}{|c|c|c|c|}
\hline Body System & Type of Congenital Anomalies & Number (n) & Percentage (\%) \\
\hline Cardiovascular system (CVS) $=28$ & $\begin{array}{l}\text { Patent ductus arteriosus } \\
\text { Ventricular septal defect } \\
\text { Congestive heart defect }\end{array}$ & $\begin{array}{c}5 \\
14 \\
9\end{array}$ & $\begin{array}{l}2.51 \\
7.04 \\
4.52\end{array}$ \\
\hline Respiratory system $(\mathrm{RS})=3$ & Trachea esophageal fistula & 3 & 1.51 \\
\hline Central nervous system $(\mathrm{CNS})=56$ & $\begin{array}{l}\text { Spinal bifida } \\
\text { Hydrocephalus } \\
\text { Anencephaly }\end{array}$ & $\begin{array}{c}29 \\
18 \\
9\end{array}$ & $\begin{array}{l}14.57 \\
9.05 \\
4.52\end{array}$ \\
\hline Gastrointestinal tract $(\mathrm{GIT})=4 \mathrm{I}$ & $\begin{array}{l}\text { Cleft lip and cleft palate } \\
\text { Omphalocele } \\
\text { Duodenal atresia } \\
\text { Inguinal hernia } \\
\text { Gastroschisis } \\
\text { Imperforate anus }\end{array}$ & $\begin{array}{c}6 \\
10 \\
4 \\
1 \\
1 \\
19\end{array}$ & $\begin{array}{c}3.02 \\
5.03 \\
2.01 \\
0.5 \\
0.5 \\
9.55\end{array}$ \\
\hline Genitourinary system (GUS) $=3$ & Hypospadias & 3 & 1.51 \\
\hline Musculoskeletal system (MSS) $=32$ & $\begin{array}{l}\text { Club foot } \\
\text { Polydactyl } \\
\text { Developmental dysplasia of the hip }\end{array}$ & $\begin{array}{c}25 \\
4 \\
3\end{array}$ & $\begin{array}{l}12.56 \\
2.01 \\
1.51\end{array}$ \\
\hline Chromosomal $=6$ & Down syndrome & 6 & 3.02 \\
\hline Multiple System $=30$ & Multiple CAs ${ }^{\mathrm{a}}$ & 30 & 15.07 \\
\hline
\end{tabular}

Notes: ${ }^{a}$ Neonates who were diagnosed with more than one CAs (neonates with spinal bifida and/or hydrocephaly or anencephaly or congestive heart defect and other body organ defect).

ward. This might be the reason to be the proportion of CAs lower in these studies compared to the current study.

The current finding shows that CNS was the most affected body system 56 (28.1\%), followed by GIT 41 (20.1\%) and MSS 32 (16.1\%) of cases, respectively. This finding comparable with the studies conducted in India, ${ }^{12}$ China ${ }^{24}$ Tanzania, ${ }^{13}$ Nigeria, ${ }^{25-27}$ and Ethiopia ${ }^{14}$ in which
CNS was the most affected system. However, the most commonly affected body system was Circulatory system in Korea, ${ }^{17}$ CVS in USA, ${ }^{20}$ GUS in Iran, ${ }^{23}$ MSS in Egypt, ${ }^{4}$ GIT in Nigeria ${ }^{28}$ and orofacial in Ethiopia ${ }^{16}$ were the most commonly affected body systems. The discrepancy might be due to sociodemographic differences. Of the total cases spinal bifida was the most common birth defect 29

\section{Trend of Congenital Anomalies}

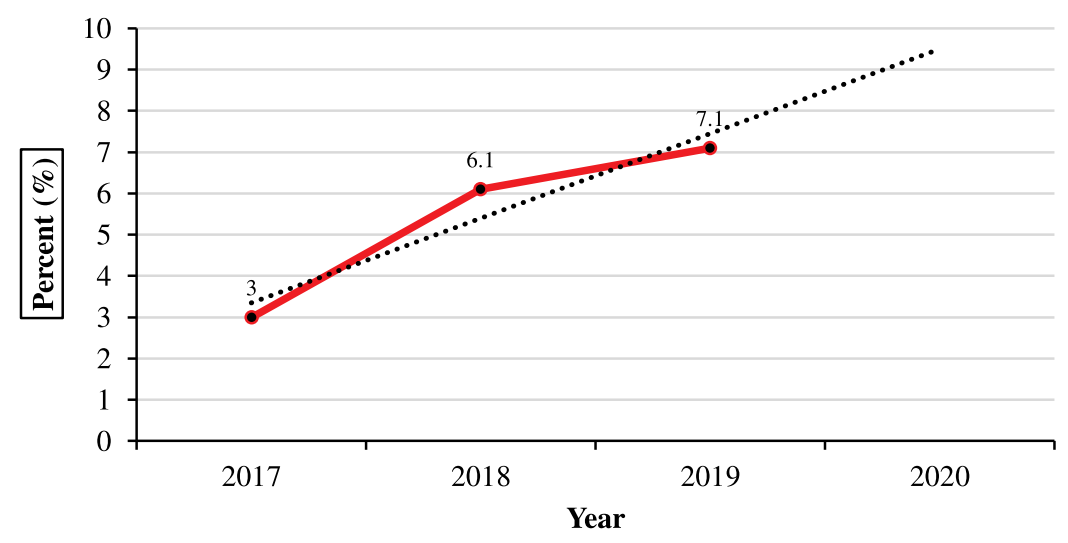

Figure 2 Trend of congenital anomalies among neonates admitted at Jimma Medical Center, Ethiopia from 2017 to 2019. 
(14.57\%); followed by clubfoot and imperforate anus 25 (12.56\%) and 19 (9.55\%) respectively.

In the present study, CAs observed more in males than females (60.3\%-males and $39.7 \%$-females) which is similar findings with the studies done in Nigeria (52\%-males and $48 \%$-females) ${ }^{29}$ Pakistan (68.3\%-males and $31.7 \%$ females), ${ }^{30}$ Ethiopia (58.5\%-males and $41.5 \%$-females) ${ }^{16}$ Also, supported by a national population-based study conducted in the United Kingdom; the risk of any CA was $26 \%$ greater in males. ${ }^{31}$ One hundred sixty-nine $(84.9 \%)$ of congenital anomalies were single, while $30(15.1 \%)$ of anomalies were multiple (more than one anomaly in one child) which is comparable with the study done in Nigeria; almost $87 \%$ of CAs were single system congenital anomaly. ${ }^{28,29}$ However, different from the studies done in Egypt and Ethiopia; $69 \%{ }^{32}$ and $95.5 \%{ }^{16}$ of the infants had a single congenital anomaly, respectively.

The linear trend of the proportion of CAs over the three year period (from the year 2017-2019) were 18 (3\%), 79 (6.1\%), and 102 (7.1\%) respectively, which shows that CAs were significantly increased over time. This might be due to increasing utilization of maternal and child health services which contribute for increasing early detection of these birth defects. According to the Ethiopian mini demographic health survey (EMDHS)-2019 report the prevalence of the utilization of institutional delivery increase from $26 \%$ in 2016 to $48 \%$ in 2019 . However, among women with alive birth, $60 \%$ of women took iron folic acid (IFA) supplement during pregnancy, and only $11 \%$ of women took IFA supplement for the recommended period of 90 or more days. ${ }^{33}$ Also, substance use might contribute for the increment from year to year; the study done in Jimma revealed that $37.9 \%$ of pregnant women were substance user; of which $65.8 \%$ of them chewed a khat followed by alcohol consumption $29.7 \%$ and cigarette smoking $2.7 \%{ }^{34}$

The limitation of this study was, could not capture live births/stillbirth/died and/or referred to other facility before admitted to the neonatology ward of JMC and since the study was a facility-based study may not be generalizable to the general population.

\section{Conclusion and Recommendation}

Based on the finding of this study the overall prevalence of CAs was high and there is an increasing linear trend of CAs over time. CNS anomalies were the most affected body system, followed by GIT and MSS of cases, respectively.

The proportions observed in the study indicated that a significant number of neonates were affected and suffered from the impacts of CAs which need immediate preventive actions such as iron-folate supplementation during preconception and early pregnancy. Therefore, policymakers, programmers, and health care providers should design strategies to create community awareness and prevention mechanism about CAs, and strengthening the care and rehabilitation services for affected patients. Further large population-based studies should be conducted to determine the clear picture of CAs and, to identify changes in the trends of CAs and factors associated to CAs.

\section{Abbreviations}

CAs, congenital anomalies; CNS, central nervous system; CVS, cardiovascular system; GIT, gastrointestinal tract; GUS, genitourinary system; IFA, iron folic acid; JMC, Jimma Medical Center; MSS, musculoskeletal system; NICU, neonatal intensive care unit; NTDs, neural tube defects; USA, United States of America; WHO, World Health Organization.

\section{Ethics Approval}

Ethical approval letter and supporting letter for the study was obtained from the school of Nursing and Midwifery, Jimma University to JMC. After explaining the purpose and benefit of the study, written permission was obtained from JMC. Confidentiality was taken into account throughout the study and the information gathered from record books was kept in a secured and locked cabinet which is used only for the research purpose. Generally, all methods in the study were carried out in accordance with the declaration of Helsinki as a statement of ethical principles for medical research involving human subjects.

\section{Acknowledgment}

The authors would like to pass their gratitude to Jimma University and Jimma Medical Center for approval and permission to carry out this study. Also, we would like to extend our thanks to Jimma Medical Center health care providers working in JMC, supervisors and data collectors for their contribution in the study.

\section{Author Contributions}

All authors (MS, TL, BF and TB) made significant contributions to the work reported in the conceptualization, execution, data acquisition, investigation, supervision, software, analysis and interpretation of data, writing of the original draft, reviewing and editing of the final draft of the manuscript. All authors have approved the 
submitted version of the manuscript, agreed on the journal to which the article has been submitted; and to be accountable for all aspects of the work.

\section{Funding}

There is no funding to report.

\section{Disclosure}

The authors declare that they have no conflicts of interest in this work.

\section{References}

1. World Health Organization (WHO). Congenital anomalies. WHO; 2016. Available from: https://www.who.int/en/news-room/fact-sheets /detail/congenital-anomalies. Accessed February 12, 2021.

2. Galina B, Tatiana C. Congenital anomaly in the structure of stillbirth and deaths of newborn children in chisinau: epidemiological study deleu raisa. Ovidius Univ Ann Econ Sci Ser. 2018;XVIII(2):251-256.

3. Heymann DL, Hodgson A, Sall AA, et al. Zika virus and microcephaly: why is this situation a PHEIC? Lancet. 2016;387 (10020):719-721. doi:10.1016/S0140-6736(16)00320-2

4. El Koumi MA, Al Banna EA, Lebda I. Pattern of congenital anomalies in newborn: a hospital-based study. Pediatr Rep. 2013;5 (1):20-23. doi:10.4081/pr.2013.e5

5. Centers for Disease Control and Prevention. Congenital anomalies-birth defects surveillance toolkit. CDC; 2019. Available from: https://www.cdc.gov/ncbddd/birthdefects/surveillancemanual/ facilitators-guide/module-1/mod1-2.html. Accessed February 12, 2021.

6. KIng IT. Controlling birth defects: reducing the hidden toll of dying and disabled children in low-income countries. Dis Control Priorities Proj. 2008.

7. Gatt M, England K, Grech V, Calleja N. Contribution of congenital anomalies to neonatal mortality rates in Malta. Paediatr Perinat Epidemiol. 2014;100(2):79-91. doi:10.1111/ppe.12206

8. Ajao AE, Adeoye IA. Prevalence, risk factors and outcome of congenital anomalies among neonatal admissions in OGBOMOSO, Nigeria. BMC Pediatr. 2019;19(1):1-10. doi:10.1186/s12887-0191471-1

9. WHO, Maternal and Child Epidemiology Estimation Group. Ethiopia - healthy newborn network [Internet]. 2018. Available from: https://www.healthynewbornnetwork.org/country/ethiopia/. Accessed February 12, 2021.

10. Gillani S, Kazmi NHS, Najeeb S, Hussain S, Raza A. Frequencies of congenital anomalies among newborns admitted in nursery of Ayub Teaching Hospital Abbottabad, Pakistan. J Ayub Med Coll Abbottabad. 2011;23(1):117-121.

11. Singh K, Krishnamurthy K, Greaves C, Kandamaran L, Nielsen AL, Kumar A. Major congenital malformations in barbados: the prevalence, the pattern, and the resulting morbidity and mortality. ISRN Obstet Gynecol. 2014;2014:1-8. doi:10.1155/2014/651783

12. Prashar N, Gupta S, Thakur R, Sharma P, Sharma G. A study of incidence of congenital anomalies in newborn: a hospital based study. Int J Res Med Sci. 2016;4(6):2050-2053. doi:10.18203/2320-6012. ijrms 20161758

13. Mashuda F, Zuechner A, Chalya PL, Kidenya BR, Manyama M. Pattern and factors associated with congenital anomalies among young infants admitted at Bugando medical centre, Mwanza, Tanzania. BMC Res Notes. 2014;7(1):1-7. doi:10.1186/1756-0500$7-195$
14. Taye M, Afework M, Fantaye W, Diro E, Worku A. Congenital anomalies prevalence in Addis Ababa and the Amhara region, Ethiopia: a descriptive cross-sectional study. BMC Pediatr. 2019;19 (1):1-11. doi:10.1186/s12887-019-1596-2

15. Dessie MA, Zeleke EG, Workie SB, Berihun AW. Folic acid usage and associated factors in the prevention of neural tube defects among pregnant women in Ethiopia: cross-sectional study. BMC Pregnancy Childbirth. 2017;17(1):1-8. doi:10.1186/s12884-017-1506-2

16. Taye M, Afework M, Fantaye W, Diro E, Worku A, Dastgiri S. Magnitude of birth defects in central and northwest Ethiopia from 2010-2014: a descriptive retrospective study. PLoS One. 2016;11 (10):1-12. doi:10.1371/journal.pone.0161998

17. Lamichhane DK, Leem JH, Park M, et al. Increased prevalence of some birth defects in Korea, 2009-2010. BMC Pregnancy Childbirth. 2016;16(1):1-10. doi:10.1186/s12884-016-0841-z

18. Cherie N, Mebratu A. Adverse birth out comes and associated factors among delivered mothers in Dessie Referral Hospital, North East Ethiopia. Womens Health Reprod Med. 2018;1(July):1-6.

19. Obu HA, Chinawa JM, Uleanya ND, Adimora GN, Obi IE. Congenital malformations among newborns admitted in the neonatal unit of a tertiary hospital in Enugu, South-East Nigeria a retrospective study. BMC Res Notes. 2012;5:2-7. doi:10.1186/ 1756-0500-5-177

20. Egbe A, Uppu S, Lee S, Stroustrup A, Ho D, Srivastava S. Congenital malformations in the newborn population: a population study and analysis of the effect of sex and prematurity. Pediatr Neonatol. 2015;56(1):25-30. doi:10.1016/j. pedneo.2014.03.010

21. Santoro M, Minichilli F, Pierini A, et al. Congenital anomalies in contaminated sites: a multisite study in Italy. Int J Environ Res Public Health. 2017;14(3):1-10. doi:10.3390/ijerph14030292

22. Zhao JP, Sheehy O, Bérard A. Regional variations in the prevalence of major congenital malformations in Quebec: the importance of fetal growth environment. J Popul Ther Clin Pharmacol. 2015;22(3):e198-210.

23. Ped JC, Press I, Press I, et al. Determining the Risk Factors of Congenital Anomalies of Newborns in Hamadan Province. 2020.

24. Zhang $\mathrm{X}, \mathrm{Li} \mathrm{S}, \mathrm{Wu} \mathrm{S}$, et al. Prevalence of birth defects and risk-factor analysis from a population-based survey in Inner Mongolia, China. BMC Pediatr. 2012;12(1):2-7. doi:10.1186/14712431-12-125

25. Akinmoladun JA, Ogbole GI, Oluwasola O. Pattern and outcome of prenatally diagnosed major congenital anomalies at a Nigerian Tertiary Hospital. Niger J Clin Pract. 2018;21(5):560-565. doi:10.4103/njcp.njcp_210_17

26. Oloyede OA, Otaigbe BE, Opara PI. Prevalence and Pattern of Birth Defects in a Tertiary Health Facility in the Niger Delta Area of Nigeria. 2017:115-121.

27. Singh S, Chukwunyere D, Omembelede J, Onankpa B. Foetal congenital anomalies: an experience from a tertiary health institution in north-west Nigeria (2011-2013). Niger Postgrad Med J. 2015;22 (3):174. doi:10.4103/1117-1936.170743

28. Ekwere EO, Mcneil R, Agim B, Jeminiwa B, Oni O, Pam S. A retrospective study of congenital anomalies presented at tertiary health facilities in Jos, Nigeria. JPCS. 2011;3(3):24-28.

29. Anyanwu L-JC, Danborno B, Hamman WO. Birth prevalence of overt congenital anomalies in Kano metropolis: overt congenital anomalies in the Kano. Univers $J$ Public Health. 2015;3(2):89-96. doi:10.13189/ujph.2015.030206

30. Raza MZ, Sheikh A, Ahmed SS, Ali S, Naqvi SMA. Risk factors associated with birth defects at a tertiary care center in Pakistan. Ital J Pediatr. 2012;38(1):1-7. doi:10.1186/1824-7288-38-68

31. Sokal R, Tata LJ, Fleming KM. Sex prevalence of major congenital anomalies in the United Kingdom: a national population-based study and international comparison meta-analysis. Birth Defects Res a Clin Mol Teratol. 2014;100(2):79-91. doi:10.1002/bdra.23218 
32. Ahmed AM. Assessment of risk factors for fetal congenital anomalies among pregnant women at Cairo University Hospitals. $\mathrm{J} \mathrm{Am} \mathrm{Sci}$. 2011;11(2):10-14.

33. Institute E public health, ICF. Mini Demographic and Health Survey: Key Indictors. 2019:136-148. Available from: www.DHSprogram. com.
34. Yadassa Tesso F, Woldesemayat LA, Birhanu Kebede D. Magnitude of substance use and associated factors among pregnant women attending jimma town public health facilities, Jimma Zone, Oromia Regional State Southwest Ethiopia. Clin Mother Child Health. 2017;14(4):1-5.

\section{Publish your work in this journal}

Pediatric Health, Medicine and Therapeutics is an international, peerreviewed, open access journal publishing original research, reports, editorials, reviews and commentaries. All aspects of health maintenance, preventative measures and disease treatment interventions are addressed within the journal. Practitioners from all disciplines are invited to submit their work as well as healthcare researchers and patient support groups. The manuscript management system is completely online and includes a very quick and fair peer-review system. Visit http://www.dovepress.com/testimonials.php to read real quotes from published authors.

Submit your manuscript here: http://www.dovepress.com/pediatric-health-medicine-and-therapeutics-journal 